\title{
BMJ Open Evaluating the feasibility of a web- based discharge education programme to improve general surgical patients' postdischarge recovery: a pilot randomised controlled trial
}

Evelyn Kang (1), ${ }^{1}$ Wendy Chaboyer, ${ }^{2}$ Georgia Tobiano @ ${ }^{2,3}$ Brigid Gillespie ${ }^{2,3}$

To cite: Kang E, Chaboyer W, Tobiano G, et al. Evaluating the feasibility of a web-based discharge education programme to improve general surgical patients' postdischarge recovery: a pilot randomised controlled trial. BMJ Open 2022;12:e054038. doi:10.1136/ bmjopen-2021-054038

- Prepublication history and additional supplemental material for this paper are available online. To view these files, please visit the journal online (http://dx.doi.org/10.1136/ bmjopen-2021-054038)

Received 02 June 2021 Accepted 20 January 2022

Check for updates

(C) Author(s) (or their employer(s)) 2022. Re-use permitted under CC BY-NC. No commercial re-use. See rights and permissions. Published by BMJ.

${ }^{1}$ School of Nursing and Midwifery, Griffith University Gold Coast Campus, Southport, Queensland, Australia ${ }^{2}$ NHMRC Centre of Research Excellence in Wiser Wound Care, Menzies Health Institute Queensland, Griffith University, Gold Coast, Queensland, Australia

${ }^{3}$ Nursing and Midwifery Education and Research Unit, Gold Coast University Hospital, Gold Coast, Queensland, Australia

Correspondence to Ms Evelyn Kang; e.kang@griffith.edu.au

\section{ABSTRACT}

Objective To assess the feasibility of implementing a web-based discharge education programme for general surgery patients both prior to and after hospital discharge.

Design, setting and participants This is a prospective, two-arm, pilot randomised controlled trial. Patients who had a general surgery procedure were recruited from a tertiary hospital between 0ctober 2020 and January 2021. Patients were randomly assigned to either the standard education or the web-based education intervention.

Intervention The web-based education comprised of three components designed to enhance patients' knowledge, skills and confidence to improve their engagement with self-care, and the ability to detect any postoperative issues that can arise during the postdischarge period.

Main outcomes and measures The primary outcome was feasibility in terms of recruitment, randomisation, retention and treatment fidelity related to intervention delivery, adherence and satisfaction. Secondary outcomes were patient activation, self-care ability and unplanned healthcare utilisation.

Results Eighty-five patients were recruited and randomised (42 control; 43 intervention). Twenty-three (27\%) were lost to follow-up. All patients received their group allocation as randomised and all patients in the intervention group received the web-based education prior to discharge. Postdischarge, patients accessed the education an average of 3 times (SD 3.14), with 4 minutes (SD 16) spent on the website. $28(97 \%)$ of the intervention patients found the content easy to understand $25(86 \%)$ found it useful and $24(83 \%)$ were satisfied with its content. There was a significant association between the intervention and patient activation $(F(1,60)=9.347$, $p=0.003$ ), but not for self-care ability and unplanned healthcare utilisations.

Conclusion This pilot study demonstrated the feasibility of implementing a web-based education programme. There was a high number of participants lost to followup, requiring additional attention in the design and implementation of a larger trial.

Trial registration number ACTRN12620000389909p.
Strengths and limitations of this study

- This is a pilot trial to test a web-based discharge education intervention that was rigorously and systematically developed for general surgery patients.

- The pilot trial was rigorously conducted to measure feasibility outcomes including treatment fidelity.

- There was lack of blinding among patients, research assistants and data analyst.

- There was a high number of patients lost to follow-up.

- The use of Google Analytics to monitor user behaviour may be unreliable.

\section{INTRODUCTION}

Postoperative complications resulting in unplanned readmission, reoperations and mortality pose significant challenges for general surgical patients. ${ }^{12}$ Of the complications resulting in readmission within 30 days, surgical wound and gastrointestinal issues have been shown to be the most common across various general surgeries after hospital discharge. ${ }^{3}$ In the US Medicare beneficiaries report, $19.5 \%$ of beneficiaries discharged after a surgical procedure and readmitted within 30 days cost the healthcare system approximately $\$ 17$ billion each year. ${ }^{4}$ In addition to the financial burden of hospital readmission, postoperative complications can negatively impact on patients' quality of life due to the challenges of prolonged recovery and functional limitations. ${ }^{56}$

\section{BACKGROUND}

Limited or ineffective discharge education can contribute to surgical patients' lack of knowledge for self-managing their postdischarge recovery. Without this knowledge, patients may miss the signs and symptoms of 
potential postoperative complications. ${ }^{78}$ The implementation of accelerated postoperative pathways to improve efficiency and enhance patient flow has culminated in shorter inpatient stays, challenging healthcare providers to develop and provide patient-centred discharge education. ${ }^{9}$ Consequently, surgical patients can be discharged home with incomplete understanding of postoperative recovery, including information on self-care and management of their postdischarge recovery. ${ }^{7}$ Additionally, researchers have shown that discharge education is often delivered at inopportune moments when patients were not receptive to learning due to their medical condition or when caregivers were absent when inpatient teaching occurred. ${ }^{10}$ The provision of discharge education is crucial for surgical patients to self-manage and monitor their postdischarge recovery and consequently improve their postoperative outcomes. ${ }^{11}$

The use of technology after hospital discharge is increasing due to its potential to bridge the knowledge gap encountered by patients after hospital discharge. ${ }^{12-14}$ Web-based interventions have been effective in supporting patients in self-regulatory behaviours such as self-care, as compared with other forms of intervention delivery. ${ }^{15}$ Despite the number of complications resulting in unplanned readmission after general surgery, interventions to improve postdischarge recovery for general surgical patients have received little attention and research. ${ }^{16}$ Therefore, we developed a web-based discharge education programme to facilitate patients' engagement in their care by improving the knowledge, skills and confidence required to self-manage their postdischarge recovery after general surgery. As recommended by the UK Medical Research Council (MRC) framework for developing and evaluating complex interventions, ${ }^{17}$ the next crucial step was to pilot the intervention by conducting a feasibility trial with scope for refinement prior to carrying out a larger definitive randomised controlled trial (RCT). This paper describes the systematic approach adopted in the implementation and testing of the web-based education programme, which may provide guidance for others who are designing and evaluating patient education interventions using web-based technology.

\section{METHODS}

\section{Aim}

The aim of this pilot study was to assess the feasibility of implementing a web-based discharge education programme for general surgery patients prior to hospital discharge to inform decision for the definitive trial. The objectives were to (1) determine the feasibility of recruitment, randomisation and retention of participants; (2) establish the fidelity of intervention delivery, adherence and satisfaction; and (3) assess if the intervention will be of potential benefit to general surgery patients by estimating the intervention's effect size on patients' activation, self-management skills and unplanned hospital utilisation.

\section{Design}

This was a prospective, two-arm, unblinded pilot RCT. The Consolidated Standards of Reporting Trials extension for randomised pilot and feasibility trials ${ }^{18}$ guided the reporting of this pilot study.

\section{Participants}

We did not set any criteria related to the effectiveness of the intervention in terms of patient outcomes as the aim of this study was to collect the data necessary to plan a definitive trial. As this was a feasibility pilot study, a formal sample size calculation was not undertaken and a target sample size between 60 and 100 was considered acceptable. ${ }^{18}{ }^{19}$ Patients were eligible if (1) they had a primary general surgical procedure defined as surgery that focused on the alimentary tract, the abdomen and its contents, breast skin and soft tissue, and the endocrine system, ${ }^{20}$ such as gastrointestinal (digestive system) procedure, thyroidectomy, hepatobiliary surgery, appendectomy, pancreatic surgery and colorectal surgery performed laparoscopically or laparotomy involving penetration into the peritoneal cavity; (2) aged $\geq 18$ years; (3) able to provide informed consent; (4) understand and speak English; and (5) able to access the web-based education intervention independently on their computer, smartphone or tablet device. We excluded (1) patients who had an ambulatory or day surgery procedure; and (2) patients discharged as hospital in the home patients or discharged to residential care as the planned discharge destination. Patients were recruited from the general surgical wards of a tertiary public hospital in Queensland, Australia. Potential patients were identified by the ward nurses, and patients who indicated interest in the study were approached by the research nurse to determine their eligibility. Patients were given time to read the information sheet provided or ask questions before giving their written consent.

\section{Randomisation}

A web-based centralised randomisation service was used to randomly assigned patients in a 1:1 ratio to receive either the standard predischarge education or the webbased discharge education. Random blocks of 4 and 6 were used. Group allocation was revealed to patients after completion of baseline data collection. Due to the nature of the intervention, patients and clinicians could not be blinded to group allocation.

Patients in both arms received standard care during their hospitalisation, including a predischarge teaching session by their healthcare providers (ie, surgeons, nurses, pharmacists, dietitian).

\section{Intervention}

The intervention was a web-based discharge education programme designed to encourage patient participation in self-care through active learning and self-assessment 
of their postoperative symptoms and recovery. The intervention development was informed by the UK MRC framework for developing and evaluating complex intervention ${ }^{17}$ and the Knowledge-to-Action Framework. ${ }^{21}$ The web-based discharge education was codeveloped with consumers and healthcare providers, ${ }^{70}$ underpinned by the principles of Knowles' adult learning theory, ${ }^{22}$ the concept of patient activation ${ }^{23}$ and recent research about discharge education for general surgical patients. ${ }^{16}$ The development of the intervention is described in detail elsewhere. ${ }^{24}$

The web-based education programme consisted of three components: (1) post general surgery warning signs; (2) post general surgery everyday care instructions; and (3) a video on surgical wound care and signs of wound complications. The first component included a traffic light system (colours were green, yellow and red) with descriptions of common warning signs of postoperative complications following general surgery. It was tiered to support general surgical patients' ability to discern between normal and abnormal postoperative symptoms, with instructions on how to act, depending on the symptom. The second component included information on the 'do's' and 'don'ts' after general surgery and included activities, surgical wound care, medication, pain management and follow-up appointments for patients to cope with their postdischarge recovery in the community. The final component consisted of an animated video about recognising potential signs and symptoms of surgical wound complications and the correct technique for removing a surgical wound dressing.

Patients in the intervention group were provided login details on how to access the website and were shown the components of the education. It took approximately 15 minutes to review the content of the online education programme. A personalised text message notification was sent 2 days after discharge to remind patients in the intervention group to access the website at home.

\section{Data collection}

At recruitment, demographic and socioeconomic data were collected to provide an overview of the sample. Patient-reported outcomes, including patient activation and patients' self-care ability, were collected during recruitment and by telephone with a research assistant 2 weeks after patients were discharged. Information on unplanned healthcare utilisation (ie, general practitioner (GP) visits, emergency department (ED) presentations) was collected during the 2-week telephone follow-up and from patients' medical chart review undertaken at day 30 . Research assistants were trained by the principal investigator and all entered data were checked for accuracy. All data were collected using an electronic data capture system known as Research Electronic Data Capture (REDCap).

\section{Measures}

\section{Primary outcome: feasibility}

The primary outcome of this pilot study was feasibility, tested against the following criteria: recruitment: $\geq 80 \%$ of eligible patients will agree to participate; randomisation: $\geq 95 \%$ of patients will receive random allocation to the treatment group; and retention: $<10 \%$ of recruited patients will be lost to follow-up. Feasibility outcomes related to treatment fidelity included delivery of the intervention, adherence to the intervention and satisfaction with the intervention.

Patients who were uncontactable for follow-up interview or who dropped out of the study post randomisation were considered lost to follow-up. Treatment fidelity related to delivery of the intervention was assessed against the criteria: $\geq 90 \%$ of patients in the intervention arm received the dose and content of the intervention as specified in the protocol. Adherence to the intervention was monitored using Google Analytics to measure the number of times patients accessed the web-based education. The total number of patient logins to review discharge education was calculated during the study period. Additional information such as the length of time spent on the website and the components of the education most frequently visited was retrieved from Google Analytics. Patient satisfaction with the intervention was collected using a short questionnaire (three questions) during the telephone follow-up. Patients in the web-based education group were asked their satisfaction with the online discharge education and its usefulness and clarity, with items measured on a 5-point Likert scale.

\section{Secondary outcomes: patient activation, self-care ability and} unplanned healthcare utilisation

Patient-reported outcome data included (1) Patient Activation Measure (PAM) ${ }^{23}$ (2) Therapeutic Self-Care (TSC) scale $^{25}$ and (3) unplanned healthcare utilisation within 30 days after discharge. This utilisation included unscheduled GP visits, ED presentations and hospital readmissions due to any reported or documented postoperative complaints or complications. The 13-item PAM scale is designed to elicit responses from a person about their attitudes towards and knowledge, skills and confidence for self-management. ${ }^{26} \mathrm{~A}$ 4-point Likert scale of response options ranging from strongly disagree to strongly agree is used to elicit endorsement of a particular statement and higher scores indicate greater activation. The total patient activation results were scored using an Excel sheet supplied by the Insignia Health Group (licensee of the PAM questionnaire), ${ }^{27}$ which sums and normalises the items on a 100-point scale. Psychometric analysis of the PAM-13 suggests good reliability and validity properties. ${ }^{26}$ The TSC scale was developed to assess self-care ability in acute care settings prehospital and posthospital discharge. The TSC scale measures patients' perceived ability for self-care, operationalised in behaviours related to taking medications, recognising and managing symptoms, carrying out activities of daily living, and managing 


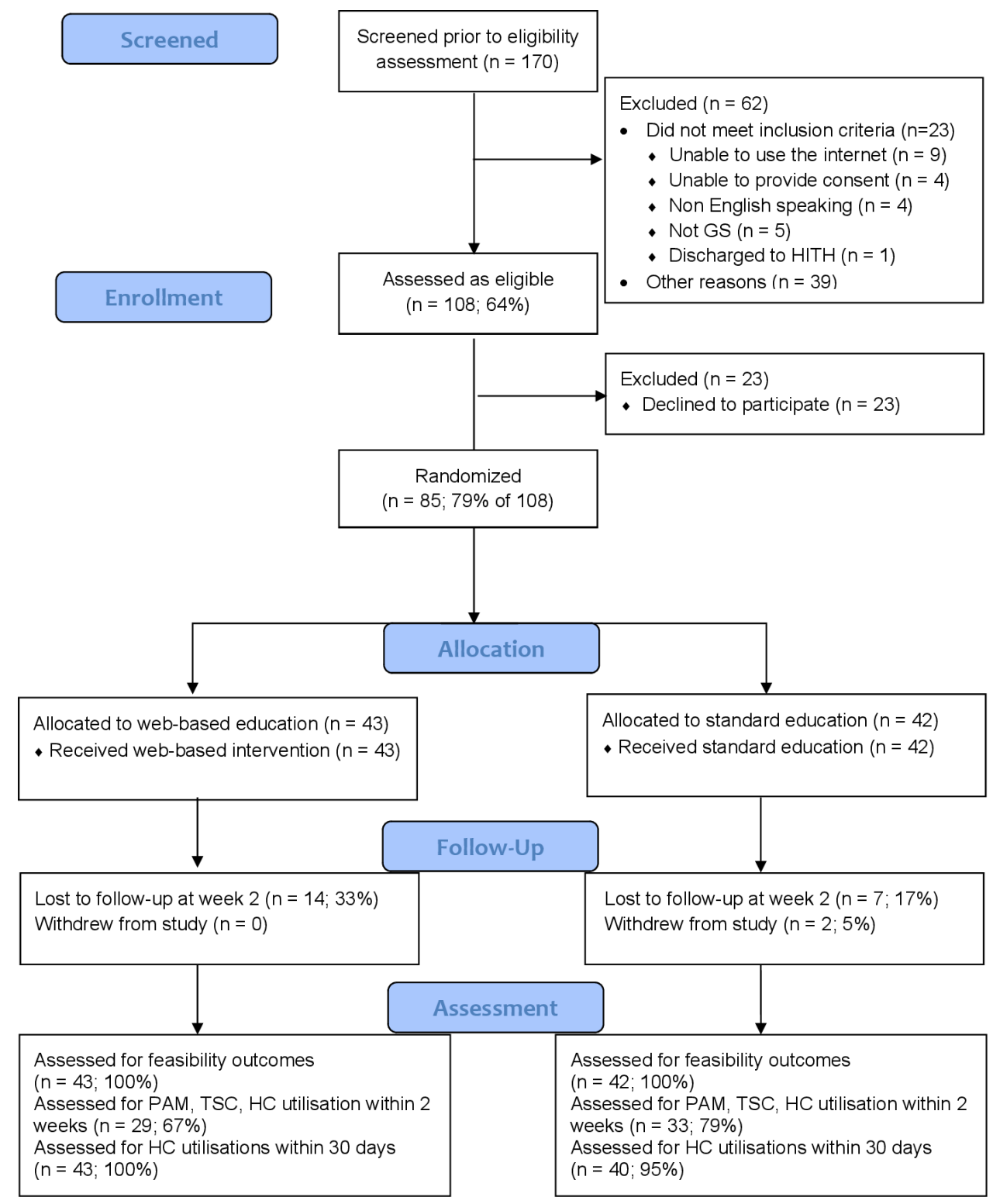

Figure 1 Flow diagram of patients through the trial. GS, general surgery; HC, healthcare; HITH, hospital in the home; PAM, Patient Activation Measure; TSC, Therapeutic Self-Care scale.

changes in condition. ${ }^{25}$ Scores can range from 1 (low self-care) to 5 (independent in self-care). The validity and reliability of the TSC scale used to measure self-care among individuals with traumatic injuries ${ }^{28}$ in home and acute care setting are well established. ${ }^{25} 29$

\section{Data analysis}

Descriptive data analysis was performed for baseline demographics and clinical outcome data. Mean and SD were used for continuous variables and frequencies and percentages calculated for categorical variables. Feasibility outcomes relating to recruitment, randomisation, retention, treatment fidelity and the proportion of missing data were assessed using descriptive statistics, appropriate to the level and distribution of the data.

Although this pilot RCT was not powered to detect comparative treatment effects between groups, an exploratory analysis of group differences was planned for the secondary outcome measures. To determine the change in patient activation and self-care ability across both groups at baseline and 2 weeks postdischarge, a two-way mixed analysis of variance (ANOVA) (within-subject factor: time; between-subjects factor: treatment) was completed. Data were tested for homogeneity of variances $(p>0.05)$ and covariances $(p>0.001)$, as assessed by Levene's test of homogeneity of variances and Box's M test, respectively. For variables with a significant interaction, further tests were performed to analyse the simple main effect of different time points in each group. Unplanned healthcare utilisation was compared using Fisher's exact or Pearson $\mathrm{X}^{2}$ test (for categorical data) as appropriate. Missing data for the outcomes patient activation, self-care ability and GP visits (unplanned healthcare utilisation) were excluded from the analysis for patients who were lost to follow-up. No imputation was required as 
Table 1 Baseline characteristics $(\mathrm{N}=85)$

\begin{tabular}{lll}
\hline Characteristics & $\begin{array}{l}\text { Web-based } \\
\text { education }(\mathbf{n}=\mathbf{4 3})\end{array}$ & $\begin{array}{l}\text { Standard education } \\
(\mathbf{n}=42)\end{array}$ \\
\hline Female, $\mathrm{n}(\%)$ & $27(63)$ & $28(67)$ \\
\hline Age, mean (SD) & $44(17.7)$ & $53(16.2)$ \\
\hline Marital status, $\mathrm{n}(\%)$ & $17(40)$ & $18(43)$ \\
\hline Married & $18(42)$ & $10(24)$ \\
\hline Never married & $5(12)$ & $10(24)$ \\
\hline Divorced & $3(7)$ & $4(10)$ \\
\hline Widowed & & $9(21)$ \\
Living status, $\mathrm{n}(\%)$ & $8(19)$ & $25(60)$ \\
\hline Alone & $30(70)$ & $8(19)$ \\
\hline Family & $5(12)$ & \\
\hline Friend &
\end{tabular}

Highest level of education, $\mathrm{n}(\%)$

$\begin{array}{lcc}\text { Primary education or none } & 2(5) & 1(2) \\ \text { Secondary education } & 22(51) & 23(55) \\ \text { Tertiary education } & 19(44) & 18(43)\end{array}$

Working situation, $\mathrm{n}(\%)$

\begin{tabular}{|c|c|c|}
\hline Full-time & $17(40)$ & $17(41)$ \\
\hline Part-time & $9(21)$ & $8(19)$ \\
\hline Not in workforce & $7(16)$ & $14(33)$ \\
\hline Unemployed & $6(14)$ & $2(5)$ \\
\hline Students & $4(9)$ & $1(2)$ \\
\hline \multicolumn{3}{|l|}{ Surgery type, n (\%) } \\
\hline Emergency & $16(37)$ & $15(36)$ \\
\hline Elective & $27(63)$ & $27(64)$ \\
\hline \multicolumn{3}{|l|}{ ASA, $n(\%)$} \\
\hline ASA 1 & $9(21)$ & $10(24)$ \\
\hline ASA 2 & $27(63)$ & $19(45)$ \\
\hline ASA 3 & $7(16)$ & $10(24)$ \\
\hline ASA 4 & $0(0)$ & $3(7)$ \\
\hline \multicolumn{3}{|l|}{ Surgical approach, n (\%) } \\
\hline Laparoscopy & $37(86)$ & $31(74)$ \\
\hline Laparotomy/open & $6(14)$ & $11(26)$ \\
\hline \multicolumn{3}{|l|}{ Procedures, n (\%) } \\
\hline Colorectal surgery & $20(47)$ & $14(33)$ \\
\hline Cholecystectomy & $10(23)$ & $13(31)$ \\
\hline Appendectomy & $5(12)$ & $2(5)$ \\
\hline Hernia repair & $3(7)$ & $5(12)$ \\
\hline Liver resection & 0 & $1(2)$ \\
\hline Splenectomy & $2(5)$ & $1(2)$ \\
\hline Other GS procedures* & $3(7)$ & $7(17)$ \\
\hline HLOS, median (IQR) & $4(2-7)$ & $3(1-7)$ \\
\hline
\end{tabular}

*Other GS procedures included procedures performed by a general surgeon (ie, laparoscopy, parathyroidectomy, exploratory laparotomy).

ASA, American Society of Anesthesiologist; GS, general surgery; HLOS, hospital length of stay.

there were no missing data for available patients. Consequently, a complete case analysis including full outcome information was used to avoid risk of bias to the results. ${ }^{30}$ For patients who were uncontactable after they were discharged (lost to follow-up), we were able to determine if they had re-presented to the ED or readmitted for any postoperative complications from their hospital chart data. All data were analysed using SPSS (V.25). Statistical significance was indicated by $\mathrm{p}<0.05$.

\section{Patient and public involvement}

The web-based discharge education intervention was codeveloped with stakeholders including clinicians and patient consumers using qualitative interviews. Clinicians were invited to codesign the implementation plan.

\section{RESULTS}

The first participant was recruited on 10 October 2020 and recruitment ended on 8 December 2020, with the last patient exiting the trial on 7 January 2021. In total, 170 patients were screened for eligibility, with 62 excluded with reasons detailed in the flow diagram (figure 1). There were 108 eligible patients approached for participation and 85 patients ( 55 female; 30 male) were recruited ( $79 \%$ recruitment rate): 43 to the intervention group and 42 to the control group. The most common reasons for refusal were because they were 'overwhelmed with postdischarge recovery' and 'did not want to be overburdened by participating in research'. Table 1 displays patients' baseline demographic and clinical characteristics. The average age of the patients was 44 years (SD 17.7, range $=18-81$ ). Most surgical procedures were colorectal surgery $(n=34 / 85,40 \%)$ and cholecystectomy $(\mathrm{n}=23 / 85,27 \%)$ performed laparoscopically $(\mathrm{n}=68 / 85,80 \%)$. All patients $(100 \%)$ accepted and received the assigned group to which they were randomised. Retention rate was lower than the predefined criteria, with $27 \%$ lost to follow-up after they were discharged and two $(5 \%)$ patients withdrew from the trial post randomisation. Reasons for withdrawal included poor health and uneventful postoperative recovery. The attrition rate was higher in the web-based education group $(n=14,33 \%)$ than in the standard education group $(\mathrm{n}=7,17 \%)$.

\section{Treatment fidelity}

There were no protocol deviations in the delivery of the intervention as all randomised patients received the intervention as specified. Contamination across groups did not occur as patients in the standard education group did not have access to the intervention. All randomised patients allocated to the intervention watched the content of web-based education programme at least once prior to hospital discharge $(n=43$, $100 \%)$. On average, after hospital discharge intervention patients logged in to the website three times (SD 3.14) after discharge. Patients spent an average duration of 4 minutes (SD 16) per session on the website. The most accessed component after hospital discharge was the "post general surgery warning signs' page, with an average of 2 minutes spent on this component and with users returning at least once to the page. Most patients found the content of the online education programme 'easy to very easy to understand' ( $n=28,97 \%)$. Further, most patients reported that they were 'fairly satisfied to very satisfied' with the content 
Estimated Marginal Means of Activation

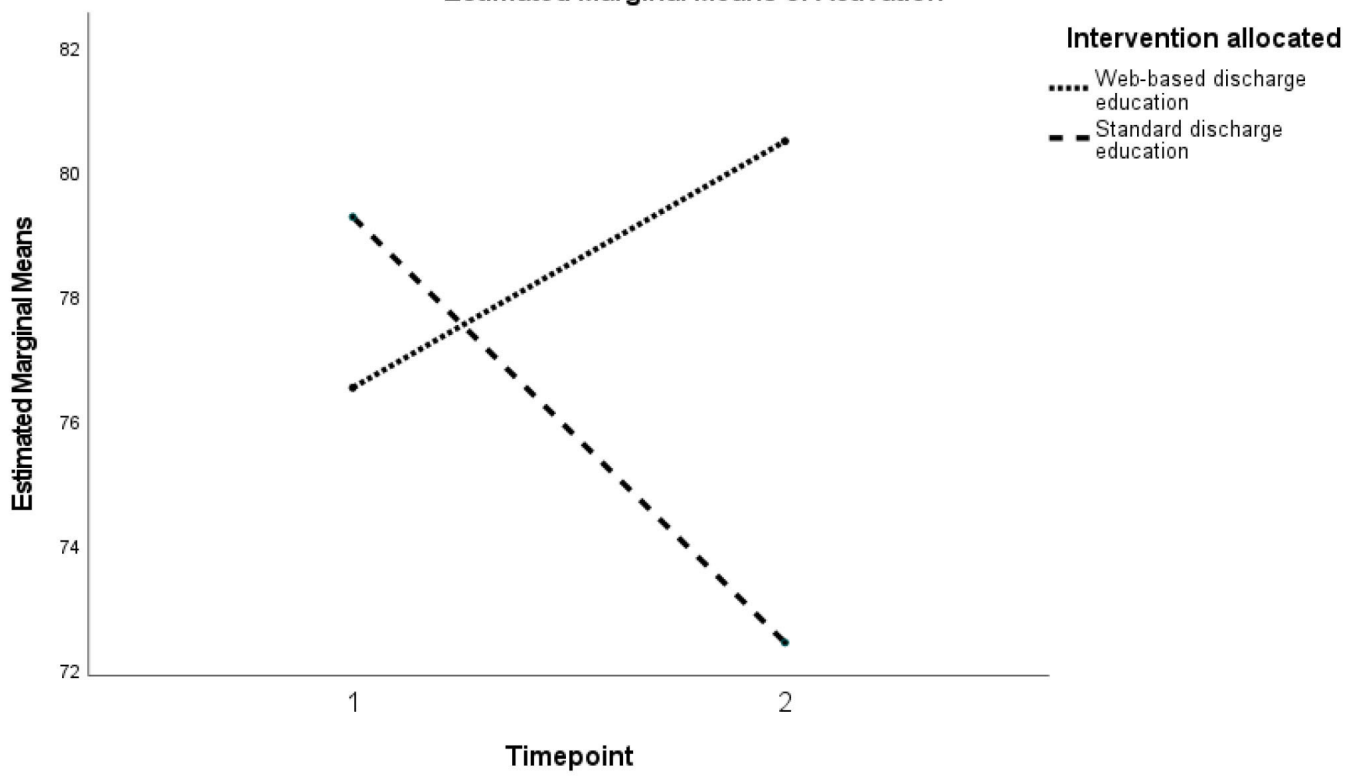

Figure 2 Mean scores for patient activation by group over time. An increase in scores represents an 'improvement' in activation.

of the programme ( $\mathrm{n}=24,83 \%)$. The education content was also well appreciated as most patients found the information on the website to be 'useful to very useful' ( $\mathrm{n}=25,86 \%)$.

\section{Patient activation}

The two-way mixed ANOVA showed a statistically significant interaction between the intervention and time on patient activation $\left(F(1,60)=9.347, \mathrm{p}=0.003\right.$, partial $\eta^{2}=0.135$; figure 2). Data presented used mean and $\pm \mathrm{SE}$, unless stated otherwise. Patient activation score was significantly higher in the intervention group post-test (2-week postdischarge)
(8.056, $\pm 3.90, \mathrm{p}=0.043)$ as compared with the standard education group, which demonstrated a decline in activation score over time $(-6.84, \pm 2.42, \mathrm{p}=0.008)$.

\section{Self-care ability}

The two-way mixed ANOVA demonstrated no statistically significant interaction between the group and time on patients' self-care ability $(F(1,60)=3.007, \mathrm{p}=0.088$, partial $\eta^{2}=0.48$; figure 3 ). The main effect of time showed a statistically significant difference in self-care ability over the period of time $\left(F(1,60)=8.934, \mathrm{p}=0.004\right.$, partial $\left.\eta^{2}=0.130\right)$. The

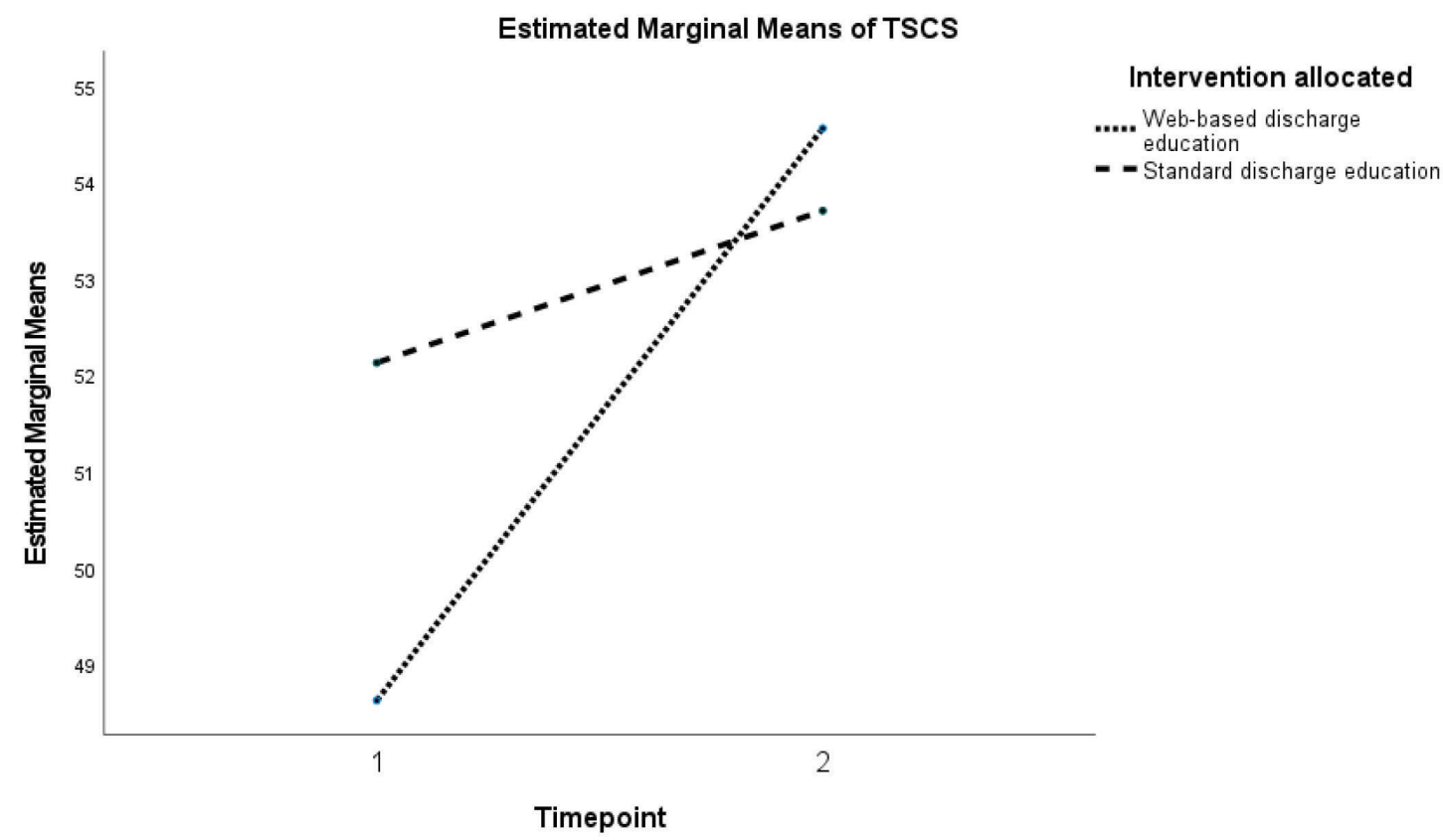

Figure 3 Mean scores for patients' self-care ability by group over time. An increase in scores represents an 'improvement' in self-care ability. TSCS; Therapeutic Self-Care scale 
Table 2 Unplanned healthcare utilisation due to postoperative complications between groups

\begin{tabular}{|c|c|c|c|c|}
\hline 2-week telephone follow-up & All $^{*}(n=62)$ & $\begin{array}{l}\text { Web-based education } \\
(n=29)\end{array}$ & $\begin{array}{l}\text { Standard education } \\
(n=33)\end{array}$ & $\mathbf{P}$ value $†$ \\
\hline GP visit, n (\%) & $13(21)$ & $5(17)$ & $8(24)$ & 0.55 \\
\hline ED presentation, n (\%) & $7(11)$ & $3(10)$ & $4(12)$ & 1.00 \\
\hline 30-day medical chart audit & All $¥(n=83)$ & $\begin{array}{l}\text { Web-based education } \\
(n=43)\end{array}$ & $\begin{array}{l}\text { Standard education } \\
(n=40)\end{array}$ & $\mathbf{P}$ value \\
\hline ED presentation, n (\%) & $10(12)$ & $4(9)$ & $6(15)$ & 0.51 \\
\hline
\end{tabular}

*Signifies the number of patients with available data during the 2-week follow-up.

$+\chi^{2}$ analyses; Fisher's exact test used.

$\ddagger$ Signifies the number of patients with available data during the 30-day chart audit.

ED, emergency department; GP, general practitioner.

main effect of group showed that there was no significant difference in mean self-care ability between the two groups $\left(F(1,60)=0.810, \mathrm{p}=0.372\right.$, partial $\left.\eta^{2}=0.013\right)$.

\section{Unplanned healthcare utilisation}

The number of unplanned healthcare utilisations was compared using Fisher's exact or $\mathrm{X}^{2}$ test. We found patients visiting their GP and presenting to $\mathrm{ED}$ due to postoperative complaints/complications at 2-week follow-up higher in the standard education group as compared with the web-based education group, although this was non-significant ( 5 of 29 $(17 \%)$ vs 8 of $33(24 \%), p=0.50 ; 3$ of $29(10 \%)$ vs 4 of 33 $(12 \%), \mathrm{p}=0.83)$. ED visits for postoperative complications and hospital readmissions within 30 days were also higher in the standard education group, although non-significant ( 4 of $43(9 \%)$ vs 6 of $40(15 \%), p=0.43 ; 1$ of $43(2 \%)$ vs 2 of $40(5 \%), p=0.51) \quad$ (table 2). The types of postoperative complications resulting in unplanned healthcare utilisation are reported in online supplemental appendix 1 .

\section{DISCUSSION}

This pilot study demonstrates the feasibility of implementing a web-based discharge education intervention for general surgery patients to actively engage in their recovery after discharge. However, several limitations and potential barriers were identified and must be addressed in the design of the main trial. This information may also inform others who are designing and evaluating web-based patient education interventions.

\section{Feasibility of the trial design}

We found recruitment of participants to the trial acceptable, with $85(79 \%)$ patients recruited from the general surgical wards within 10 weeks. The short period of recruitment suggests that the number of general surgeries at this hospital site is sufficient to achieve the target sample size. However, we found collecting follow-up data for this population challenging with a high attrition rate (27\%) despite multiple strategies undertaken to improve participants' retention. Missing data due to loss to follow-up were higher in the web-based education group (33\%) as compared with the standard education group (17\%), although this finding is not surprising given the greater burden placed on intervention participants. ${ }^{31}$ Regardless, it is important to note that more than $20 \%$ of attrition poses serious threats to internal validity. ${ }^{32}$ To deal with the missing outcomes, we restricted analysis to those with full outcome information using a complete case analysis instead of using multiple imputation methods. Multiple imputation may be the preferred method in dealing with missing data but this method remains controversial. ${ }^{334}$ When planning for the larger definitive trial, changes to the current design and programme implementation to improve participants' retention rate are necessary. An extensive strategy to minimise loss to follow-up could include good communication between study staff and participants, incentives for participants to continue, flexibility with follow-up scheduling and reducing participant burden. ${ }^{356}$ Efforts should be made to ensure that participants are well informed of the details of the study while promoting study relevance to participants. ${ }^{35}$

\section{Feasibility with treatment fidelity}

Implementation fidelity influences the internal and external validity of trials and is critical to the successful translation of interventions into practice. ${ }^{37}$ Monitoring usage data is valuable in exploring patients' adherence to health interventions to inform strategies for achieving optimal engagement with and effectiveness of the intervention. ${ }^{38}$ While web-based interventions provide many advantages (ie, accessibility, low cost) as compared with inperson delivery interventions, specific methodological challenges have been identified in the implementation of web-based education. ${ }^{39}$ Notwithstanding care and strategies taken by the research team to improve patients' uptake of the intervention, actual use of the intervention was relatively low based on the statistics captured in Google Analytics. However, this was not surprising as it has been observed in other trials of fully automated online interventions. ${ }^{40}$ For our study, we surmised that the short time spent and multiple logins may be due to patients referring to each component of the education programme as a checklist to self-assess their symptoms and health condition. Considering the low level of utilisation observed, future work requires incorporation of automated reminders using text message prompts to maximise user engagement with the intervention. 
The satisfaction questionnaire on the content of the web-based programme was rated highly by most patients, suggesting the intervention was clear, applicable and useful. As the web-based education was developed with extensive patient and consumer input, it is likely that patients' satisfaction with the programme is the result of an intervention that met the needs of the end users. Health interventions using codesign techniques with stakeholders are known to be effective in modifying patients' behaviour and improving their health as compared with interventions developed without stakeholder engagement. ${ }^{4142}$

\section{Potential benefits of the intervention}

We observed a significant improvement in patient activation but not self-care ability and healthcare utilisations for patients who received the web-based education. Nonetheless, these findings were exploratory and not adequately powered to support hypothesis testing for effectiveness, although it is plausible a correlation exists between patient activation, self-care ability and unplanned healthcare utilisation from the use of the web-based programme. Other research supports the association between patients' activation level and improved health behaviours. ${ }^{43} 44$ The study by Dumitra $e t a t^{43}$ found that patients with low levels of activation were associated with increased postdischarge healthcare use, hospital stay and complications after major surgery. Our results illustrate the possibility of the wide benefits of a web-based education, given in addition to standard education provided at the hospital, in improving postoperative outcomes. ${ }^{45}$

As previously described in our qualitative study, surgical patients want to have an active role in their postdischarge recovery, but this is challenging because of the limited knowledge and skills they possessed. ${ }^{7}$ The adaptation to the current standard discharge education can increase patients' understanding, attitudes and expectations for their postdischarge recovery to effectively self-manage their health. For clinicians, the web-based education programme creates an opportunity for patient participation as the intervention is designed to give patients the confidence to communicate any concerns and seek information from their healthcare providers regarding their health and treatment plan. During this study, the time spent on orientating patients to the website took approximately $10-15$ minutes. We therefore conclude that the intervention can be incorporated as part of the discharge teaching process for nurses as the time required to apply the education programme is low and feasible. The web-based education was not designed to replace the current in-hospital discharge teaching provided by the clinicians. Rather, the web-based education programme provides patients with an additional and alternative source of information to facilitate patients' participation in self-care after discharge. It remains essential to activate patients to be attentive to the changes in their clinical conditions, as well as the actions that need to be undertaken to avoid or minimise complications to improve their postoperative outcomes.

\section{Limitations}

This study has some limitations. First, blinding of patients and research assistants was not practical in the trial. To reduce response bias, we refrained from using language that may suggest to patients that the intervention may be superior to the standard education during the consent process, advertisement or follow-up conversation. Second, as this was a doctoral project, the student leading the data analysis was unblinded to group allocation. Future trials should include blinding of the data analyst in the study design. Lastly, although using Google Analytics as a tool to monitor user behaviour with the intervention is useful in ensuring treatment fidelity, the results should be interpreted with caution. For example, the number of users visiting the website may be inaccurate as a new client identification is provided each time a user logs in from a different browser or switches to a different device. However, the same user will still be counted as a new user, ${ }^{46}$ thus creating data discrepancy. Future work should incorporate a combination of evaluation tool or methods (ie, surveys, interviews) to provide an accurate interpretation of participants website behaviour.

\section{CONCLUSION}

This pilot study demonstrates the feasibility of implementing a web-based discharge education programme for general surgical patients to actively engage in their own recovery after hospital discharge. However, some crucial limitations and barriers were identified. A future definitive trial seems imperative with modification to the current design and programme implementation including measures to improve participants' retention, data analyst blinding and evaluation of website behaviour.

Acknowledgements The authors thank all patients of the study unit that participated in this study. The authors also acknowledge the help of the nursing staff of the study unit that supported the study.

Contributors EK designed the work, collected, analysed and interpreted the data, and wrote the draft of the manuscript. WC, BG and GT contributed to the design and methodology, provided critical feedback on drafts of the manuscript, supervised the study, and finally approved this version to be published. EK accepts full responsibility for the work and the conduct of the study, had access to the data, and controlled the decision to publish.

Funding This study was supported by grants from the Australian College of Perioperative Nurses Queensland (ACORN).

Competing interests None declared.

Patient consent for publication Not required.

Ethics approval This study involves human participants and was approved by the ethics committees of Gold Coast Health (HREC/2019/QGC/60858) and Griffith University (GU ref no: 2020/474). Participants gave informed consent to participate in the study before taking part.

Provenance and peer review Not commissioned; externally peer reviewed.

Data availability statement No data are available. Access to individual patientlevel data is not available for this study.

Supplemental material This content has been supplied by the author(s). It has not been vetted by BMJ Publishing Group Limited (BMJ) and may not have been peer-reviewed. Any opinions or recommendations discussed are solely those of the author(s) and are not endorsed by BMJ. BMJ disclaims all liability and responsibility arising from any reliance placed on the content. Where the content includes any translated material, BMJ does not warrant the accuracy and reliability 
of the translations (including but not limited to local regulations, clinical guidelines, terminology, drug names and drug dosages), and is not responsible for any error and/or omissions arising from translation and adaptation or otherwise.

Open access This is an open access article distributed in accordance with the Creative Commons Attribution Non Commercial (CC BY-NC 4.0) license, which permits others to distribute, remix, adapt, build upon this work non-commercially, and license their derivative works on different terms, provided the original work is properly cited, appropriate credit is given, any changes made indicated, and the use is non-commercial. See: http://creativecommons.org/licenses/by-nc/4.0/.

\section{ORCID iDs}

Evelyn Kang http://orcid.org/0000-0001-8253-1638

Georgia Tobiano http://orcid.org/0000-0001-5437-0777

\section{REFERENCES}

1 Kazaure HS, Roman SA, Sosa JA. Association of postdischarge complications with reoperation and mortality in general surgery. Arch Surg 2012;147:1000-7.

2 Gibson A, Tevis S, Kennedy G. Readmission after delayed diagnosis of surgical site infection: a focus on prevention using the American College of Surgeons National Surgical Quality Improvement Program. Am J Surg 2014;207:832-9.

3 Tevis SE, Kohlnhofer BM, Weber SM, et al. Postdischarge complications are an important predictor of postoperative readmissions. Am J Surg 2014;208:505-10.

4 Jencks SF, Williams MV, Coleman EA. Rehospitalizations among patients in the Medicare fee-for-service program. N Engl J Med 2009;360:1418-28.

5 Pinto A, Faiz O, Davis R, et al. Surgical complications and their impact on patients' psychosocial well-being: a systematic review and meta-analysis. BMJ Open 2016;6:e007224.

6 Hesselink G, Flink M, Olsson M, et al. Are patients discharged with care? A qualitative study of perceptions and experiences of patients, family members and care providers. BMJ Qual Saf 2012;21:i39-49.

7 Kang E, Gillespie BM, Tobiano G, et al. General surgical patients' experience of hospital discharge education: a qualitative study. J Clin Nurs 2020;29:e1-10

8 Tanner J, Padley W, Davey S, et al. Patient narratives of surgical site infection: implications for practice. J Hosp Infect 2013;83:41-5.

9 Taurchini M, Del Naja C, Tancredi A. Enhanced recovery after surgery: a patient centered process. J Vis Surg 2018;4:40.

10 Kang E, Tobiano GA, Chaboyer W, et al. Nurses' role in delivering discharge education to general surgical patients: a qualitative study. J Adv Nurs 2020b;76:1698-707.

11 Collinsworth AW, Brown RM, James CS, et al. The impact of patient education and shared decision making on hospital readmissions for COPD. Int J Chron Obstruct Pulmon Dis 2018;13:1325-32.

12 Martorella G, Côté J, Racine M, et al. Web-based nursing intervention for self-management of pain after cardiac surgery: pilot randomized controlled trial. J Med Internet Res 2012;14:e177-e77.

13 Fredericks S, Martorella G, Catallo C. A systematic review of webbased educational interventions. Clin Nurs Res 2015;24:91-113.

14 Newnham H, Barker A, Ritchie E, et al. Discharge communication practices and healthcare provider and patient preferences, satisfaction and comprehension: a systematic review. Int J Qual Health Care 2017;29:752-68.

15 Saidinejad M, Zorc J. Mobile and web-based education: delivering emergency department discharge and aftercare instructions. Pediatr Emerg Care 2014;30:211-6.

16 Kang E, Gillespie BM, Tobiano G, et al. Discharge education delivered to general surgical patients in their management of recovery post discharge: a systematic mixed studies review. Int $J$ Nurs Stud 2018;87:1-13.

17 Craig P, Dieppe P, Macintyre S, et al. Developing and evaluating complex interventions: the new Medical Research Council guidance. BMJ 2008;337:979-83.

18 Eldridge SM, Chan CL, Campbell MJ, et al. CONSORT 2010 statement: extension to randomised pilot and feasibility trials. BMJ 2016;355:i5239.

19 Thabane L, Ma J, Chu R, et al. A tutorial on pilot studies: the what, why and how. BMC Med Res Methodol 2010;10:1.

20 The American Board of Surgery. Specialty of general surgery defined, 2017. Available: http://www.absurgery.org/default.jsp? aboutsurgerydefined
21 Graham ID, Logan J, Harrison MB, et al. Lost in knowledge translation: time for a map? J Contin Educ Health Prof 2006;26:13-24

22 Knowles MS. The adult learner: a neglected species. 4th edn. Houston, Texas: Gulf Publishing Company, 1990.

23 Hibbard JH, Stockard J, Mahoney ER, et al. Development of the patient activation measure (PAM): conceptualizing and measuring activation in patients and consumers. Health Serv Res 2004;39:1005-26.

24 Kang E, Gillespie BM, Tobiano G, et al. Development of a web-based discharge education intervention to improve the postdischarge recovery of general surgical patients. J Nurs Scholarsh;337.

25 Sidani S, Doran DI. Development and validation of a self-care ability measure. Can J Nurs Res 2014;46:11-25.

26 Hibbard JH, Mahoney ER, Stockard J, et al. Development and testing of a short form of the patient activation measure. Health Serv Res 2005;40:1918-30.

27 Insignia Health. Patient activation measure, 2020. Available: https:// www.insigniahealth.com/research/research-licenses [Accessed Jan 2021].

28 Chaboyer W, Ringdal M, Aitken L, et al. Self-care after traumatic injury and the use of the therapeutic self care scale in trauma populations. J Adv Nurs 2013;69:286-94.

29 Sidani S. Effects of patient-centered care on patient outcomes: an evaluation. Res Theory Nurs Pract 2008;22:24-37.

30 Hollis S, Campbell F. What is meant by intention to treat analysis? Survey of published randomised controlled trials. BMJ 1999;319:670-4.

31 Lazovski J, Losso M, Krohmal B, et al. Benefits and burdens of participation in a longitudinal clinical trial. J Empir Res Hum Res Ethics 2009;4:89-97.

32 Bell ML, Kenward MG, Fairclough DL, et al. Differential dropout and bias in randomised controlled trials: when it matters and when it may not. BMJ 2013;346:e8668.

33 van der Heijden GJMG, Donders ART, Stijnen T, et al. Imputation of missing values is superior to complete case analysis and the missing-indicator method in multivariable diagnostic research: a clinical example. J Clin Epidemiol 2006;59:1102-9.

34 Jakobsen JC, Gluud C, Wetterslev J, et al. When and how should multiple imputation be used for handling missing data in randomised clinical trials - a practical guide with flowcharts. BMC Med Res Methodol 2017;17:162.

35 Kearney A, Rosala-Hallas A, Bacon N, et al. Reducing attrition within clinical trials: the communication of retention and withdrawal within patient information leaflets. PLoS One 2018;13:e0204886.

36 Gillies K, Kearney A, Keenan C, et al. Strategies to improve retention in randomised trials. Cochrane Database Syst Rev 2021;3:MR000032.

37 Moncher FJ, Prinz RJ. Treatment fidelity in outcome studies. Clin Psychol Rev 1991;11:247-66.

38 O'Brien HL, Toms EG. What is user engagement? A conceptual framework for defining user engagement with technology. J Am Soc Inf Sci 2008;59:938-55.

39 Eaton LH, Doorenbos AZ, Schmitz KL, et al. Establishing treatment fidelity in a web-based behavioral intervention study. Nurs Res 2011;60:430-5.

40 Wangberg SC, Bergmo TS, Johnsen J-AK. Adherence in Internetbased interventions. Patient Prefer Adherence 2008;2:57-65.

41 Sampson EL, Feast A, Blighe A, et al. Pilot cluster randomised trial of an evidence-based intervention to reduce avoidable hospital admissions in nursing home residents (better health in residents of care homes with nursing-BHiRCH-NH study). BMJ Open 2020;10:e040732.

42 Jessup RL, Osborne RH, Buchbinder R, et al. Using co-design to develop interventions to address health literacy needs in a hospitalised population. BMC Health Serv Res 2018;18:989.

43 Dumitra T, Ganescu O, Hu R, et al. Association between patient activation and health care utilization after thoracic and abdominal surgery. JAMA Surg 2021;156:e205002.

44 Lin M-Y, Weng W-S, Apriliyasari RW, et al. Effects of patient activation intervention on chronic diseases: a meta-analysis. J Nurs Res 2020;28:e116.

45 McDonall J, de Steiger R, Reynolds J, et al. Patient activation intervention to facilitate participation in recovery after total knee replacement (MIME): a cluster randomised cross-over trial. BMJ Qual Saf 2019;28:782-92.

46 Clark DJ, Nicholas D, Jamali HR. Evaluating information seeking and use in the changing virtual world: the emerging role of Google analytics. Learn Pub 2014;27:185-94. 